\title{
PHRYGIA EPIKTETOS'TAKİ MEN KÜLTÜ ÜZERINE NOTLAR
}

\section{sosis atumase DERGISI}

ANKARA UNIVERSITY JOURNAL

OF SOCIAL SCIENCES

10.33537/sobild.2019.10.1.4

\section{Makale Bilgisi}

Gönderildiği tarih: 21-12-2018

Kabul edildiği tarih: 05-01-2019

Yayinlanma tarihi: 30.01.2019

\section{Article Info}

Date submitted: 21-12-2018

Date accepted: 05-01-2019

Date published: 30.01.2019

\section{Anahtar sözcükler}

Ay-tanr Men, Phrygia Epiktetos, Dağlık Phrygia, Yerel Kültler, Pagan Monoteizmi, Ölüm, Aile, Çocuk

\section{Keywords}

Moon-God Men, Phrygia Epictetus, Highlands of Phrygia, Local Cults, Pagan Monotheism, death, family, child.

\section{NOTES ON THE CULT OF MEN IN PHRYGIA EPICTETOS}

\section{Hülya BOYANA}

Doç.Dr., Ankara Üniversitesi, DTCF, Tarih Bölümü; boyanahulya@gmail.com

\section{$\ddot{O} z$}

Men, Hellenistik ve Roma Dönemleri boyunca İtalya'dan Pontus'a kadar sürekli tapınım görmüş ve ay ile özdeşleştirilmiş bir tanrıdır. Kökeni hakkında tartışmalar sürmekle birlikte, genel kabul olarak bir Anadolu ve İran tanrisı olduğu üzerinde durulmaktadır. Kültü, değişik coğrafyalarda farklı özellikler almış ve yeraltı, ölüm, bereket, kadın, çocuk, aile ve adalet gibi kavramlarla özdeşleştirilmiştir. Bunun yanında, diğer pek çok tann ve tannça gibi, tapınım gördüğü merkezlerin yerel tanrısı olarak karşımıza çıkmaktadır. Hellenistik ve Roma dönemlerinde, Büyük Phrygia içinde izole bir yapıya sahip olan Phrygia Epiktetos mikro coğrafyasındaki Men tapınımı, Phrygia - Lydia ve Phrygia - Pisidia sınırına göre oldukça seyrek olmakla birlikte, bölgede bulunan diğer kültlere göre daha arka planda kalmış görünmektedir. Epiktetos'ta ölüm, aile, çocuk ve şifa ile özdeşleştirilmiş olan Men, özellikle Hekate ile çift oluşturmuş ve kimi durumlarda Asklepios'un oğlu çocuk-tanrn Telesphoros ile özdeşleştirilmiştir. Aldiğı o pavós ve túpavvos gibi sifatlarla pagan monotheist bir karakter kazanmış ve Hiristiyanliğa geçişte bir basamak oluşturmuştur.

\begin{abstract}
Men is a god worshipped throughout the Hellenistic and Roman Periods, from Italy to Pontus. Although the debates on its origin continue, it is mainly emphasized that it is an Anatolian and Persian god. God took different characteristics in different geographies and was basically identified with concepts such as underground, death, fertility, women, children, family and justice, as well as being accepted as the local god of the place where he worshiped. Men worship in Phrygia Epictetus, the area of Phrygian culture was and has a relatively isolated structure compared to other regions, seems to be more local structure and remained background. Men who appear to be identified with death, family, children and healing in the region associated with Hecate and identified with child-god Telesphoros, son of Asclepius. He also exhibited a pagan-monotheist structure with ephitets such as o pavos and iúpavvos, and formed a step in the transformation of the pagan religion to Christianity.
\end{abstract}

\section{Giriş}

Ay Tanrı Men (Mñv), MÖ 3. yüzyıldan MS 3. yüzyıla kadar İtalya'dan Pontus'a kadar uzanan geniş bir alan içinde tapınım görmüş, kökeni ve nitelikleri hakkında tartışmalara konu olmuş bir tanrıdır. Epigrafik ve nümizmatik verilerin azımsanmayacak derecede görünür olması ve adına tapınaklar yapılmasına rağmen, ayla ilişkili olan Artemis, Hekate, Selene ve Hermes gibi tanrı ve tanrıçalardaki gibi klasik Hellen geleneğince bilinen bir mitosu yoktur. Buna rağmen, farklı coğrafyalarda aile kurumu, kadınlar ve çocukların koruyucu tanrısı, şifacı tanrı, bereket tanrısı, yeraltı tanrısı, adalet tanrısı, şans tanrısı ve gök tanrı olarak karşımıza çıkmaktadır. Bazen o pavós veya túpavvos gibi epitetlerle ile tüm atfedilen sıfatlarını kapsayan bir tanrıya dönüştügü anlaş1lmaktadır. Bu durum, pagan monoteizmi 
olarak bilinen dinsel dönüşümün özelliklerini de üzerinde taşımakta ve tektanrıcılığa geçiş sürecinde bir basamak olarak görünmektedir. ${ }^{1}$

Anadolu'da Men tapınımının en yoğun görüldüğü bölgeler Lydia ve Pisidia ile bu iki bölgenin Phrygia ile olan sınırlarıdır. Tanrının Lydia'daki kült merkezinin oldukça önemli bir tarım ve ticaret merkezi olan Kula Vadisi olduğu düşünülmektedir. Bu bölgeden Men ile ilgili tespit edilen en erken metin MS 66 67 yıllarına, en geç metin ise MS 269 - 70 yıllarına tarihlenmektedir. Phrygia'da ise Men kültü ile ilgili en fazla epigrafik ve nümizmatik veriye, Epiktetos olarak bilinen ve batıda Örencik Ovası'ndan, doğuda Alpu Ovası'na, kuzeyde Eskişehir - Bilecik sınırı, güneyde Seyitgazi ile sınırlanan alanda ulaş1lmıştır. Tanrı, bu bölgenin yerel özellikleri ile kaynaşmış ve hem ikonografisi hem de teolojik nitelikleri buna göre farklı biçimlere girmiştir. (Harita-1)

Bu çalışma, birbirine bağlı iki temel üzerinde bulunmaktadır. Bunlardan ilki, tanrının Phrygia Epiktetos'taki yayılımı ve bu bağlamda tanrının Phrygialı olma olasılığının tartışılması, diğeri kültün temel özelliklerinin ortaya çıkarılmasıdır. Kült hakkında tespit edilen belgeler hem Anadolu genelinde hem de Phrygia Epiktetos'ta epigrafik ve nümizmatik belgeler ile kült merkezleri olduğu düşünülen yerleşimlerde bulunan heykelciklerdir. Bu eserlerin tarihi MS 2. yüzyıl ile MS 3. yüzyıl aralığında değişmektedir. Bu tarih aralığı aynı zamanda bu çalışmanın zaman sınırını oluşturmaktadır. Bu bağlamda, Ay-Tanrının bu tarihsel ve coğrafi perspektifte ele alınması, Hıristiyanlığın, gizem kültlerinin, Yeni Platoncu ve Epikürosçuluk gibi felsefi sistemlerin yükselişte olduğu bir dönemde, yerel kültlerin bu dönüşümdeki yerini daha belirgin şekilde çizmemizi sağlayacaktır.

\section{Phrygia Epiktetos'ta Men Kültü ve Teolojik Dinamikleri}

MS 2. yüzyıldan itibaren Anadolu'nun iç bölgelerdeki yerel kültürler, kendi kimliklerini duyurmaya başlamış ve yaygın kültler ile yerel inanışlar arasında bir kaynaşmaya ortaya çıkmıştır. Bu dönüşüm, bir tanrının farklı bölgelerdeki tapınımı söz olduğunda daha belirgin hâle gelmekte ve böylelikle o tanrının ya da kutsal varlığın, kendi özünü koruyarak, tapınım gördüğü yerlere göre farklı kılıklara büründüğü gözlemlenebilmektedir. Öyle ki tek bir Zeus ya da tek bir Artemis yoktur, farklı maskeler altında farklı niteliklere sahip pek çok Zeus ve pek çok

\footnotetext{
1 Bkz. S. Mitchell, P. Van Muffelen (ed.), One God: Pagan Monotheism, Cambridge, 2010. "Pagan Monoteizmi" terimi tarihsel olarak tartışmalı bir kavram olsa da, özellikle MS 1 ve 3.yüzyıllar arasında çok tanrılı dinlerdeki bazı tanrı ve tanrıçaların, diğer tanrı ve tanrıçaların özelliklerini de kendi üzerinde toplaması ancak geride kalan tanrı ve tanrıçaların reddedilmemesiyle oluşan bu dinsel olguyu açıklayacak başka bir kavram henüz oluşturulmamıştır.
} 
Artemis vardır. Zeus, bir gök tanrısıyken bereket tanrısına dönüşebilir, Artemis bir yerde doğa tanrıçası ya da bir avcı tanrıçayken, bir başka yerde ölümün sembolü hâline gelebilir. Hatta ay ile ilişkili bir başka tanrıçanın (örneğin Hekate'nin ya da Selene'nin) niteliklerini alabilir. ${ }^{2}$ Men de ay ile ilisskilendirilen bir tanrı olarak, pek çok toplum tarafından bu gök cismine yüklenen su, bitki, ölüm, doğum, kadın, aile, bereket, yeralt1, gök ve erginlenme gibi kategorileri, bazen tek tek, bazen de bir kaçı birlikte olmak üzere, bölgeden bölgeye farklılaşarak kendinde toplamıştır. ${ }^{3}$ Ay-tanrı Men’in Epiktetos'taki görünümü de bu türden bir senkretizmi sergilemektedir

Kült, günlük yaşam ve toplumla ilgili birden çok olgu çevresinde gelişmiştir. Phrygialı toplulukların tarıma dayalı sosyo-ekonomik karakteri, ister bölge kökenli, isterse başka coğrafyalardan gelmiş olsun, tüm dinsel görüngüleri de bu temelde dönüşmeye zorlamıştır. Bu bölgedeki Zeus kültünde olduğu gibi ${ }^{4}$ Men’in, bir aytanrı olmasından kaynaklı göksel niteliği, bereket ve kurtarıcılık olgusu ile bütünleştirilmiştir ${ }^{5}$ Men adına bir köyün, yerleşimin ya da ailenin sunduğu adaklar, topluluğun yaşamı ve bunun sürdürülmesi için tanrının önemli bir rolde olduğunu göstermektedir. Hatta Eskişehir'in Söpüren Köyü'nde Vezeaeta köylülerinin adadığı bir yazıtta, söz konusu adağın dikilmesinin bizzat tanrının emri olduğundan bahsedilmektedir. ${ }^{6}$ Men'in bu tür toplulukların tanrıs1 olmas1, onun bereket ve "kurtuluş" özelliği, Attika'da tespit edilen iki rölyef üzerine

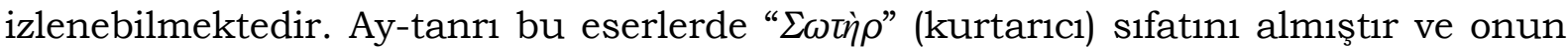
huzurunda bulunan ve çeşitli sunular hazırlayan aile üyelerinin karşısında bulunmaktadir. ${ }^{7}$ (Resim 1 ve 2)

\footnotetext{
2 Genelde Hekate ile özdeşleştirilen üçlü tanrıça formu, çoğu zaman Hekate ile birlikte Persephone, Demeter, Selene ya da Artemis'in betimlemesidir; bkz. W. Berg, "Hecate: Greek or 'Anadolian'?", Numen, Say1:21, No.2, Leiden, 1974, s.128 - 140.

${ }^{3}$ Men ile ilgili genel bir inceleme için bkz. A. Türkan, "Men, Mensis, Moon: Ay Tanrı Men, Özellikleri ve Kültü”, Ömer Çapar’a Armağan, ed. T. Yiğit vd., Ankara, 2012, s.333 - 348.

4 Buna en iyi örnek Zeus Bronton tapınımıdır; bkz. E. Akyürek - Şahin, "Phrygia'dan Yeni Zeus Bronton Adakları", Arkeoloji ve Sanat, Sayı: 122, İstanbul, 2006, s.89 - 124; E. Akyürek - Şahin, "Bihynia'dan Yeni Zeus Bronton Adakları", Olba, Say1:20, Mersin, 2012, s.345 - 382.

5 CMRDM I, No. 88, 93, 97, 98, 105 ve 148. Men'in bereketle ilişikisini vurgulayan en iyi belgelerden biri Arkadia'da bulunan ancak Batı Anadolu'dan getirildiği düşünülen bir rölyeftir. Burada Men'in

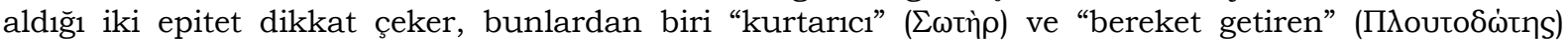
unvanları onun tarımla ilisskilendirildiğini göstermektedir. Bkz. SEG 28, No.1168.
}

6 MAMA V, No.150; SEG 27, No.1175; CMRDM I, No.93; "Vezeaeitalılar Men İtalikos için emir uyarınca bunu diktiler".

7 CMRDM I, No. 1-2. 


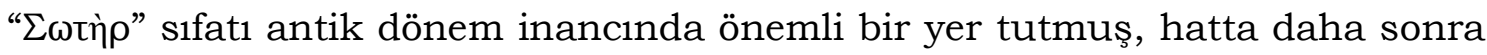
Hristiyanlığa da altarılmıştır. Bu, genellikle hastalık ve fiziksel zarardan korunmak için tanrılara yakıştırılmıştır. ${ }^{8}$ Dorylaion (Eskişehir) kentinin sınırları içinde bulunan bir yazıtta, "Papa" isimli bir babanın, oğlunun kurtuluşu için Men'e adakta bulunduğu yazmaktadır. 9 Söz konusu stel Men'e adanmıştır ancak bir at üstünde cüppeli olarak betimlenen erkek figür, şifacı tanrı Asklepios'un oğlu çocuk-tanrı Telesphoros'u anımsatmaktadır. ${ }^{10}$ (Resim 3) Sicilya kökenli bir ikiz tanrı olan Pallakoi için adanan başka bir yazıtta ise Phryg başlı̆̆ takmış Ay-Tanrı Men betimlenmiştir. Ramsay, bu yazıtta Men'in Telesphoros ile birleştirilerek Pallakoi oluşturduğunu öne sürmektedir. ${ }^{11}$

Telesphoros'un çocukların koruyucu tanrısı olması onun Men ile bir senkretizm teşkil etmesini sağlamış olmalıdır. Anadolu ve Hellas'ın belirli bölgelerinde Men, tek başına ve doğrudan bu amaçla tapınım görmüştür. Örneğin Kula Vadisi'nde bulunan, elinde horoz ve kozalak tutan figürinde, tanrının kendisi bir bebek olarak betimlenmiştir. ${ }^{12}$ (Resim 4) Bu betim, onun Telesphoros ile bir başka ortak özelliğini göstermektedir. Epiktetos bölgesinde Ay-tanrıyı çocuk ya da bebek olarak gösteren bir tasvir bulunmamaktadır ancak Telesphoros'un ikonografisinin bu noktada Men'e uygulandiğı düşünülmektedir. Phrygia Epiktetos'un önemli kentlerinden biri olan Aizanoi'da bulunan bir başka yazıtta da, Diogenes isimli bir babanın oğlu için diktiği stel${ }^{13}$ ve yine Eskişehir'in Avdan Köyü'nde tespit edilen ve çiftlerin çocukları için adadığı iki yazıt14 tanrının çocuklarla olan ilişkisini açık bir şekilde göstermektedir.

\footnotetext{
8 CMRDM III, s. 1 vd.

9 CMRDM I, No.91; G. Redet, Nouvelles Archives des Missions Scientifiques et Litteraires, c.6, Paris, 1895 , s.573, no.23.

10 Telesphoros'un kökeni tam olarak bilinmese de en eski tapınım merkezi şimdilik Pergamon'dur. Pergamon'da yoğun bir Asklepios kültü olduğunu biliyoruz, nihayetinde Telesphoros da Hygeia ile birlikte Asklepios'un iki çocuğundan biri olarak betimlenmektedir ki bu tanrının tapınımı da genel olarak bu ikisi ile birlikte görünmektedir. Kültü ise genellikle sağlık ve çocuklarla ilgili bir tapınım çevresinde gelişmiştir. bkz. W. Wroth, "Telesphoros", The Journal of Hellenic Studies, Say1:3, Cambridge, 1882 s. 283 - 300. Phrygia'da Telesphoros kültünün varlığ sikkeler üzerinde de görünmektedir: BMC, rev. Hygieia, Telesphoros, Asklepios; Midaion. Midaion'da üzerinde Men bulunan Caracalla dönemine ait bir adet sikke de bulunmaktadır; CMRDM II, Midaeum I, lev.XXV.
}

11 W.M. Ramsay, “Artemis-Leto and Apollo-Lairbenos, JHS, Say1:10, 1889, s. 227, no.25.

12 CMRDM I, No. 64; ayrica bkz. Schlumberger, "Terres Cuites de Coloé", Gazette Archeologique, Say1:6, Paris, 1880, s.191- 196.

13 MAMA IX, No.62.

14 MAMA V, No.132 ve CMRDM I, No.94; MAMA V, No.133 ve CMRDM I, No.95. 
Kütahya'nın Hasanlar Köyü'nde tespit edilen bir yazıtta Kyntiane isimli bir kadının ölen çocuğu için Hekate ile birlikte Men'e adakta bulunması, ay tanrının yalnızca çocukların sağlığ ve esenliği ile değil, aynı zamanda onların ruhlarının esenliği ile ilişkilendirildiğini göstermektedir. Yazıtın sonuna eklenen "Paian'ın oğlu" tamlaması, bu tanrı ile Men arasında baba-oğul ilişkisi kurulduğunu göstermektedir. Paian, Phryg-Trak kökenli bir hava ve yeraltı tanrısı olan Sabazios'un Hellenleşmiş biçimidir. Söz konusu tanrının bazı durumlarda Phrygia'daki Asklepios kültü ile bütünleşmesi, Men ile Asklepios'un oğlu Telesphoros arasında kurulan senkretizm ihtimalini daha da güçlendirmekte, dahası bu bağ, anne-baba-çocuk üçlüsünün varlığının da gündeme gelmesini sağlamaktadır. ${ }^{15}$ Roma İmparatorluk Dönemi Akdeniz Dünyası'nda tanrı ve tanrıçaların bu şekildeki birleşmeleri, pek çok gizem dini ve Hıristiyanlığın kendisinde de görüleceği üzere oldukça yaygındır. ${ }^{16}$

Kütahya'da bulunan ve hem mezar hem de adak işlevi olan bir başka yazıtta, elinde polos ve meşalelerle Hekate, elinde palmiye dalı tutan ve sirtında hilal bulunan Men ve sağ elinde balta tutan, sol eliyle ise bir köpeği besleyen bir figürle birlikte görünmektedir. ${ }^{17}$ Söz konusu ailenin çiftçi olduğunu taşın altındaki sabandan anlamaktayız. Bununla birlikte, Hekate'nin yeraltı ve ölümle ilgili bağlantısı düşünüldüğünde, Men’in de bir ailenin mezar taşında, ölüm ve yeraltı ile ilişkilendirildiği sonucuna ulaşılabilir. (Resim 5)

Söz konusu mezar stelinin bir başka ilginç yanı, stelin, tanrıların yanında, ölen iki kişi için adanmış olmasıdır. Bu, özellikle Epiktetos'un dağlık kısımlarında görülen ölü kültü geleneğini akla getirmektedir. Phrygia'da tektanrıcılığa giden süreçte önemli bir rol oynayan bu kült, "ölümden sonra kurtuluş" düşüncesine dönüşerek sonraki dini sisteme aktarılmıştır.18 Ay-tanrı Men'in de koruyucu, bereket ve yeraltı tanrısı olarak bu dönüşümün içinde yer alması tesadüf olmasa

\footnotetext{
15 J.A.R. Munro, "Inscriptions from Mysia", JHS, Say1:17, Cambridge, 1897, s.283, no.48 ve CMRDM I, No.89: "Kyntianos'un kızı Kyntiane, burada yatan çocuğu için Hekate ve Paian'ın oğlu Men'e adadı."

16 Bkz. C. Picard, "Sabazios, Dieu Thraco-Phrygien: Expansion et Aspects Nouveaux de Son Culte", Revue Archeologique, Say1: 2, Paris, 1961, s. 129 - 176.

17 CMRDM I, No.99: “Aphion ve eşi Gaius bu mezarı Kurtarıcı Hekate ve Apellas ile Gaius'un anısını onurlandırmak için adadı. Times Marmatenos”

18 Bkz. A. Türkan, "Dorylaion Antik Kenti ve Taşrasında Ölüm Anlayışı”, ESOGÜ TD, Sayı:1, Eskişehir, 2018, s. 7 vd.
} 
gerekir. Bu durum, dönemin sosyo-ekonomik yapısının bir yansımasıdır ve pek çok yerel kült bu dönüşüme, kurdukları senkretik yapılarla katkı sağlamıştır. ${ }^{19}$

Men’in Phrygia Epiktetos’ta aldığı diğer bir epithet ise “ởpavós”tur. Tanrının ay ile ilişkisi düşünüldüğünde, ona göksel bir özellik yüklenmesi normal görünmektedir. Ancak bu aynı zamanda onun varlık üzerindeki geniş iktidarının da bir sembolü olmalıdır. Ay tanrısı, kapsayıcı bir gök/hava tanrısına dönüşmüştür. $\mathrm{Bu}$, tektanrıcılığa giden süreçteki başka bir izdir. ${ }^{20}$ Yine "Túpavvos" (hükümdar, yönetici) sıfat1, onun yüksek hükmüne atıfta bulunur. ${ }^{21}$ Hatta Pessinus'ta tespit edilen bir yazıtta bu sıfat, tanrının adiyla birlikte Attys'in bir epitheti olarak da kullanılmıştır. ${ }^{22} \mathrm{Bu}$, Men’in bölgedeki diğer tanrılarla senkretizm oluşturma meylinin başka bir ifadesidir.

Tüm bunların yanında, Ay-tanrının belirli bir yerleşimin ya da coğrafyanın adını sıfat olarak taşıdığı durumlar da görülmektedir. Burada, bu kısmın başında söz ettiğimiz üzere, Men’in bir topluluğun tanrısı olarak ortaya çıkması arasında bir paralellik bulunmaktadır. Söpüren'de bulunan bir adakta "Iтaגıкós", Seyitgazi'de bulunan bir başka adakta ise bir etnik isim olduğu düşünülen "tuıtevos" sıfatını taşımaktadır. ${ }^{23}$ Kotiaeion (Kütahya) antik kenti sınırlarında yer alan bir adak stelinde, tanrının sıfatı "Arpaıos" şeklindedir. Araştırmacılar, bu sıfatın kentin akropolisi ile ilişkili olabileceğini düşünmektedir. ${ }^{24}$ Bununla birlikte, söz konusu

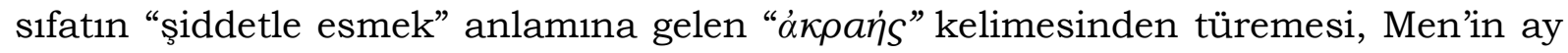
ve gök ile olan ilişkisi düşünüldüğünde daha makul bir öneri olacaktır.

\section{Men'in Kökenleri ve Phrygialılık Sav1}

Ramsay, Men'in Phrygialı bir tanrı olan "Manes"ten türediğini öne sürmektedir. ${ }^{25}$ Benzer şekilde, Erzen, Ramsay’in iddiasından yola çıkarak tanrının Anadolu'nun yerli tanrısı olduğunu, kökeninin Hititlere kadar dayandığını dile getirmiş, buna kanıt olarak, Yazılıkaya, Malatya ve Kargamış'taki kaya

\footnotetext{
19 E. İznik, "Pagan Bir İmparatorluğun Hristiyan Bir İmparatorluğa Dönüşümü: Geç Antik Çağ'da Roma İmparatorluğu”, Doğu-Batı, Sayı: 49, İstanbul, 2009, s.47 vd.

20 SEG 28, No.1174; MAMA V, no.132.

21 MAMA V, No.80.

22 CMRDM III, s.97.

23 CMRDM I, No.99.

24 SEG 28, 1168.

25 W.M. Ramsay, Cities and Bischoprics of Phrygia, c.1.1, Oxford, 1895, s.169.
} 
kabartmalarında betimlenen ay tanrısını göstermiştir. ${ }^{26}$ Ramsay'e göre Men’in klasik dönemlerdeki ikonografisi arkaik bir formdan türemiştir. Betimlemelerde sırtında bulunan hilalin bir yanlış anlaşılmadan ibaret olduğunu, bunların daha eski dönemlerdeki kanat betiminden türetildiğini öne sürmektedir ki, Erzen’in de tanrının kökeni hakkında dayandığı zemin budur. ${ }^{27}$

Lane’in öne sürdüğü ikinci görüş ise tanrının İran kökenli olabileceğidir. Lane, Men isminin, Pers dinindeki ay perisi Mao'dan türemiş olduğunu iddia etmekte ve bunu ay-tanrının Anadolu'da pek çok kez birlikte gösterildiği Artemis ile Pers tanrıçası Anahita arasındaki ikonografik benzerlikle desteklemektedir.28 Strabon'un Pontus krallarının tahta çıktıklarında Men'in adına yemin ettiği ve bu tanrının Pontus'un krali tanrısı olduğu hakkında yazdıklarına atıfta bulunmuş ve bunu Pontusluların kendilerini Perslere dayandırmasıyla paralel yorumlamıştır. ${ }^{29}$

Tüm bu yorumların ötesinde, Men tapınımının coğrafi yayılımında kronolojik bir sorun bulunmaktadır. Hellas'ta tanrıya ilişkin en erken buluntular MÖ 3.yy'a aittir. Başta Sounion olmak üzere Eretria, Atina, Peiraieus ve Thorikos'ta bulunan eserler kurumsal bir kült yapısını işaret etmektedir. ${ }^{30}$ Lane bu buluntulara bakarak burada sistematik bir kült olduğunu öne sürmekte ve bu eserlerin Menagyrtai isimli bir rahip topluluğuna ait olduğunu belirtmektedir. Bu kült daha sonra Pers köleler tarafından iyiden iyiye geliştirilmiştir. Lane tanrının bu alt sınıftaki yayılımıyla, bu bölgedeki buluntuların azlığı arasında bağlantı kurmaktadır. ${ }^{31}$ Buluntulara göre kült, MÖ 2.yy'dan itibaren Anadolu'da kendini göstermeye başlamıştır. Buradaki en erken buluntu Galatia'da, kral Deiotarus dönemine tarihlenen bir sikkedir (yak. MÖ 105 - MÖ 42/41). ${ }^{32}$ Tapınımın en yoğun görüldüğü Lydia ve Pisidia'da ise en erken buluntular MS 1.yy'a tarihlenmektedir. Phrygia Epiktetos’taki en erken örnekler ise

\footnotetext{
26 A. Erzen, "Ay Tanrısı Men’in Ad1 ve Menşei Hakkında”, Belleten, sayı: 65, Ankara 1953, s.3.

27 W.M. Ramsay, 1895, s.294.

28 CMRDM III, s. 113.

29 Strab. VII, 331; VII, 8,19.

30 CMRDM I, No. 1 - 17.

31 CMRDM I, No.12-13; CMRDM III, s. 1 vd.

32 CMRDM II, Galatia I; lev.1V.
} 
MS 2. yüzy1la aittir. ${ }^{33} \mathrm{Bu}$ geniş coğrafya ve mevcut kronolojideki problemler, Men'in kökeni hakkında da sağlıklı bir yorum yapmayı zorlaştırmaktadır.

Men’in ikonografisi doğuludur. Genellikle "Phryg Başlı̆̆ı" olarak geçen ancak Hellenlerin Persleri belirtmek için de kullandığı bir başlıkla temsil edilir. ${ }^{34}$ Tanrının Hellen Mitolojisi'nde herhangi bir yerinin olmamas1, onun Hellen toplulukları tarafından nispeten geç bir dönemde tanındığını göstermektedir. Lane’in öne sürdüğü gibi kültün buraya taşınmış olması büyük bir olasılıktır. Bu bağlamda tanrının kökenlerini Hellas'ta aramak pek akılcı olmayacaktır. Lane’in kültün Persler tarafından bölgeye getirildiğine dair iddiası, Pontus ve diğer etimolojik ayrıntılar da dikkate alındığında oldukça güçlü görünmektedir. Tanrının Lydia ve Pisidia'nın Phrygia sınırında gördüğü yoğun tapınım, Ramsay’in Phryg tanrısı Manes üzerinden yürüttüğü Phryg kökeni varsayımını da kuvvetlendirmektedir.

Kültün bu bölgelerdeki yaygınlığı Phrygia Epiktetos’ta izlenmemektedir. Tanrı, kentlerde değil, daha çok kırsal alanda popüler olmuştur. Nakoleia ile Dorylaion arasında kalan dağlık kırsal bölge, tanrının izlerine daha sık rastladığımız alandır. ${ }^{35}$ (Harita 2). $\mathrm{Bu}$ alan, Phryg kültürünün MS 2. yy'da dahi kendini korumayı başardığı bölgedir. Bunu, söz konusu alanda tespit edilen ve MS 1. yüzyıl ile MS 3. yüzyıl arasında tarihlenen yazıtlarda Phrygcenin Hellen alfabesiyle kullanılmasından anlamaktayız. ${ }^{36}$ Eğer, Men’in kökenleri Phryglere dayanıyorsa, bu kapalı kültür alanı, Kybele, Attys ve Zeus Bronton kültlerinde olduğu gibi, ay-tanrı tapınımı hakkında daha fazla veri sağlaması gerektiğini düşünmek yanlış olmayacaktır. Diğer yandan, bölgede -belki de yerel- bir ay kültünün bulunması ve

33 CMRDM I, No.22 - 27; Bithynia'da ki Men tapınımı da oldukça seyrektir ve bölgedeki en erken buluntu MS 2.yy'a aittir. Bkz. H. Boyana, "Nikomedeia Kenti ve Men Kültü”, Uluslararası Gazi Akça Koca ve Kocaeli Tarihi Sempozyumu Bildirileri, c.1., ed. H. Selvi, M. B. Çelik, Kocaeli 2015, s. 61 - 71.

${ }^{34} \mathrm{Bu}$ daha çok Hellenlerin Ionia'nın Doğusunda kalan halkları göstermek için kullandığı bir betimdir, bkz. E. Hall, "When Did the Trojans Turn into Phrygians? Alcaeus 42.15", Zeitschrift für Papyrologie und Epigraphik. Say1: 73, 1988, s.15-18.

35 CMRDM I, No. 89 - 99.

36 Calder, Phrygce'nin bölgede günlük yaşamda konuşulmaya devam ettiğini, ancak Phryglerin zaten zayıf olan yazı kültürünün Hellenistik geleneğin altında yok olduğunu dile getirmektedir. Bölgede bulunan Yeni Phrygce yazitlar için bkz. W.M. Calder, "Corpus Inscriptionum Neo-Phrygiarum II", Journal of Hellenic Studies, Say1:33, 1913, s.97-104; W.M. Calder, "Corpus Inscriptionum NeoPhrygiarum III", Journal of Hellenic Studies, Say1:46, No.1, 1926, s.22 - 28; A. Lubotsky, "New Phrygian Inscription No.48: palaeographic and linguistic comments", Frigi e Frigio. Atti del 1st Simposio Internazionale Roma, 16-17 Octobre 1995, Roma, 1997, s.115 - 130. Dağlik Phrygia gibi iç bölgelerde epigrafik gelenek MS 2.yüzyılda gelişim göstermiştir. Bundan önce bölgedeki yazı geleneği oldukça sınırlıdır. Hatta Phryg krallığı dağıldıktan ve Phryg kültürü MÖ 3.yüzyıl süresince etkisini iyiden iyiye yitirdiğinde, bu dağlık bölgede yaşayan topluluklar yazıyı bırakma eğilimi göstermiş ve dışarıya karşı geliştirilen bu direnç ancak imparatorluk döneminde kırılmıştır. Hellenistik kültürün kurumlarıyla birlikte bölgeye girmesiyle taşra kültürünün ifadesi mümkün hâle gelmiştir bkz. P. Thonemann, Phrygia: "An Anarchist History, 950 BC - AD 100", Roman Phrygia, Cambridge, 2013, s.1 - 40. 
çeşitli tanrı ve tanrıçaların da bu kült çevresinde birleşmesi de olasılıklardan biridir. Dolayısıyla, Epiktetos'taki Men tapınımı Phryg dininde daha geri planda kalmış yerel bir tanrının Hellenistik yansıması da olabilir.

\section{Sonuç}

Sonuç olarak, Phrygia Epiktetos’taki Men, kentlerde görünen bir kültten çok, kırsalda tapınım gören yerli bir tanrı olarak karşımıza çıkmaktadır. Tanrı bu bölgede daha yoğun olarak bereket, doğum, ölüm, aile ve çocuk ile özdeşleştirilmiştir, aile ve topluluğun esenliği için kendisine adaklar yaptırılmıştır. Birleştiği tanrı ve tanrıçalar da bu özelliklerini yansıtmaktadır. Bölgede, Men ile Hekate ve Telesphoros arasında doğrudan bağlantı kurulmuştur. Men'in Hekate ile birlikteliği, Lydia'daki Artemis ile olan birlikteliğini andırmaktadır. Diğer yandan, tanrı ve tanrıçanın karı-koca ya da anne-oğul olarak bir araya getirilmesi dönemin karakteristiğidir. Men’in Telesphoros ile özdeşleştirilmesi, tanrının kurtarıcı ve çocukların tanrısı olarak da insanlar arasında tapınım gördüğ̈̈nü göstermektedir.

Tanrının pek çok özelliği bir araya toplaması, bölgedeki monoteist eğilimin de

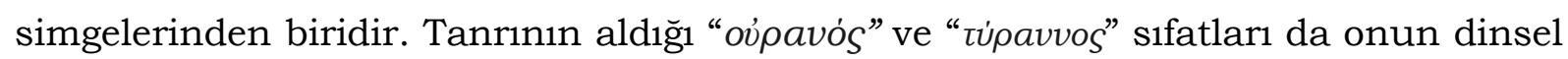
anlamda müritleri tarafından oldukça kudretli, adeta bir tek tanrı gibi görüldüğünü hissettirmekte, ayı farklı epifanilerin birleştiği bir varlığa dönüştürmektedir. Bu durum, hiç değilse bölgesel olarak Hıristiyanlığa geçişi kolaylaştırmış olmalıdır.

Bunların ötesinde, Phrygia Epiktetos'taki Men kültü, söz konusu tanrının tapınım gördüğü diğer yerlere göre oldukça zayıftır. Bu bölgenin Phryg kültürünün odak bölgelerinden biri olması, tanrının olası Phryg kökenine de şüpheyle bakılmasına neden olmaktadır. Dolayısıyla buradaki Men kültünün, tanrının hem ikonografik hem de teolojik içeriği göz önünde bulundurulduğunda, senkretik bir yapı sergilediği, belki de yerli bir ay-tanrı ile Men’in birleştirildiği akla gelmektedir. $\mathrm{Bu}$ durumda, Lane'in Men'i İran'a dayandıran savı, tanrının kökeni hakkında yapilabilecek en makul yorum gibi durmaktadır. Yine de bu yorum kesinlikten uzaktır. Kültün etimolojik ve ikonografik bir aktarım mı yoksa bir senkretizmi mi ifade ettiğini anlamak için tanrının hem coğrafyalararası olarak hem de ay ile ilişkilendirilen diğer bölgesel tanrı ve tanrıçalarla karşılaştırmalı olarak ele alınması gerekmektedir. 


\section{Bibliyografya ve K1saltmalar}

Akyürek - Şahin, E., "Phrygia'dan Yeni Zeus Bronton Adakları", Arkeoloji ve Sanat, Say1: 122, İstanbul 2006, s.89- 124.

Akyürek - Şahin, E., "Bihynia'dan Yeni Zeus Bronton Adakları”, Olba, Sayı:20, Mersin 2012, s.345-382.

Berg, W., “Hecate: Greek or 'Anatolian'?”, Numen, Say1:21, No.2, Leiden 1974, s.128 -140 .

Boyana, H. "Nikomedeia Kenti ve Men Kültü”, Uluslararası Gazi Akça Koca ve Kocaeli Tarihi Sempozyumu Bildirileri, c.1., ed. H. Selvi, M. B. Çelik, Kocaeli 2015, s. $61-71$.

Calder, W.M., "Corpus Inscriptionum Neo-Phrygiarum II", Journal of Hellenic Studies, Say1:33, 1913, s.97-104

Calder, W.M., “Corpus Inscriptionum Neo-Phrygiarum III”, Journal of Hellenic Studies, Say1:46, No.1, 1926, s.22 - 28;

CMRDM I: Lane, E. N., Corpus Monumentorum Religionis Dei Menis, c.I (Leiden 1971.

CMRDM II: Lane, E. N., Corpus Monumentorum Religionis Dei Menis, c.II, Leiden 1975.

CMRDM III: Lane, E. N., Corpus Monumentorum Religionis Dei Menis, c.III, Leiden 1976.

Erzen, A., “Ay Tanrısı Men’in Adı ve Menşei Hakkında”, Belleten, say1: 65, Ankara 1953, s. 1 - 14 .

Hall, E., "When Did the Trojans Turn into Phrygians? Alcaeus 42.15", Zeitschrift für Papyrologie und Epigraphik. Say1: 73, 1988, s.15-18.

İznik, E., "Pagan Bir İmparatorluğun Hristiyan Bir İmparatorluğa Dönüşümü: Geç Antik Çağ'da Roma İmparatorluğu”, Doğu-Batı, Sayı: 49, İstanbul 2009, s.47 - 58.

Lubotsky, A., "New Phrygian Inscription No.48: palaeographic and linguistic comments", Frigi e Frigio. Atti del 1st Simposio Internazionale Roma, 16-17 Octobre 1995, Roma 1997, s.115 - 130.

MAMA V: Monumenta Asiae Minoris Antiqua, ed. C.W.M. Cox, A. Cameron, Manchester 1937. 
Mitchell, S., P. Van Muffelen (ed.), One God: Pagan Monotheism, Cambridge 2010. Munro, J.A.R., "Inscriptions from Mysia”, JHS, Say1:17, Cambridge 1897, s.268 293.

Picard, C., "Sabazios, Dieu Thraco-Phrygien: Expansion et Aspects Nouveaux de Son Culte", Revue Archeologique, Say1: 2, Paris 1961, s. 129 - 176.

Ramsay, W.M., “Artemis-Leto and Apollo-Lairbenos, JHS, Say1:10, 1889, s.216 230.

SEG: Supplementum Epigraphicum Graecum, ed. H.W. Pleket, R.S. Stroud vd., Leiden 1923.

Strab.: Strabon, Coğrafya, çev: Adnan Pekman, İstanbul1969.

Thonemann, P., Phrygia: "An Anarchist History, 950 BC - AD 100", Roman Phrygia, Cambridge 2013, s. 1 - 40.

Türkan, A., “Men, Mensis, Moon: Ay Tanrı Men, Özellikleri ve Kültü”, Ömer Çapar’a Armağan, ed. T. Yiğit vd., Ankara 2012, s.333 - 348.

Türkan, A., "Dorylaion Antik Kenti ve Taşrasında Ölüm Anlayışı", ESOGÜ TD, Say1:1, Eskişehir 2018, s. 7 - 22. 


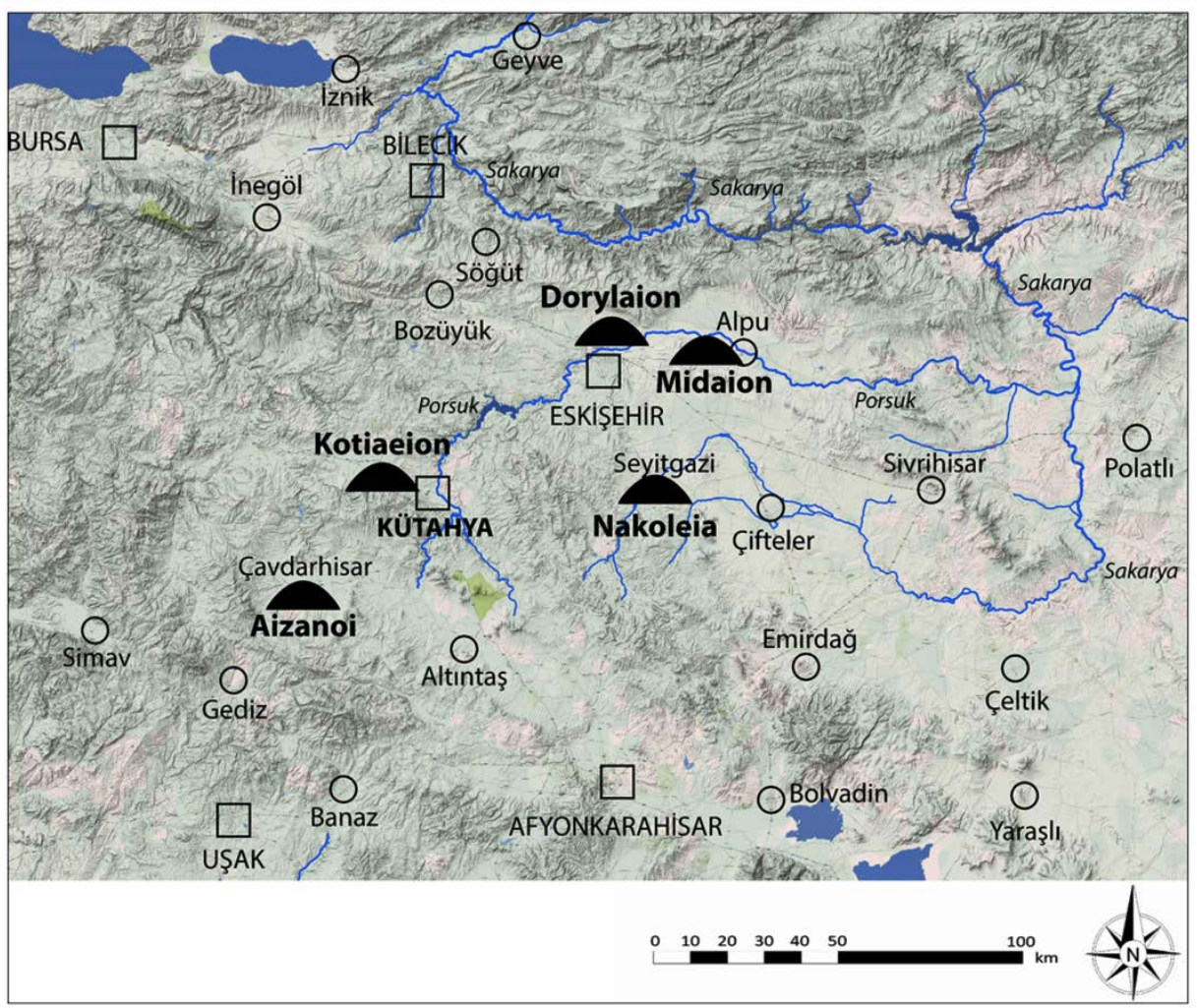

Harita 1: Phrygia Epiktetos ve Kentleri

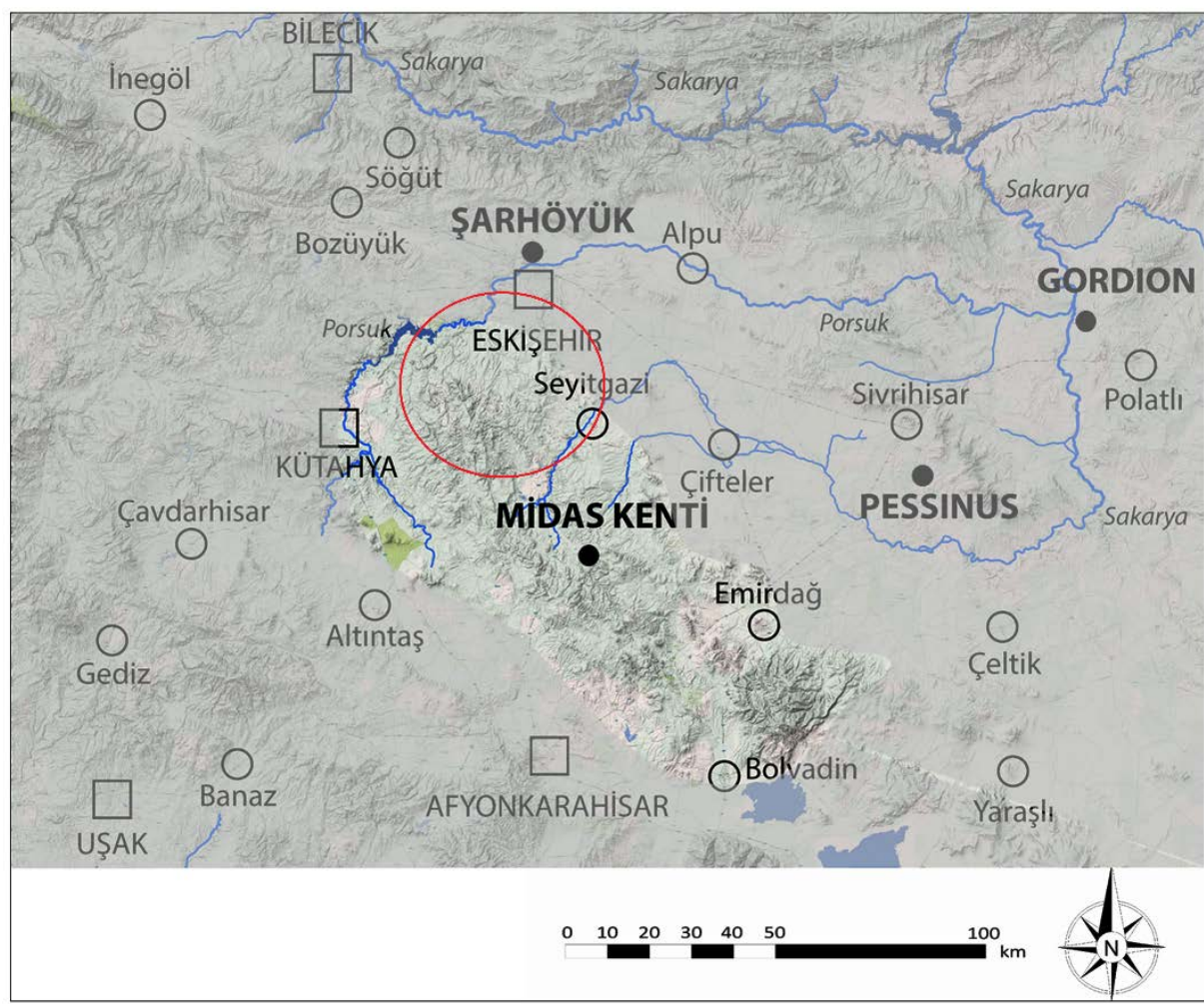

Harita 2: Dağlık Phrygia ve Men Kültünün yoğunluk gösterdiği bölge 


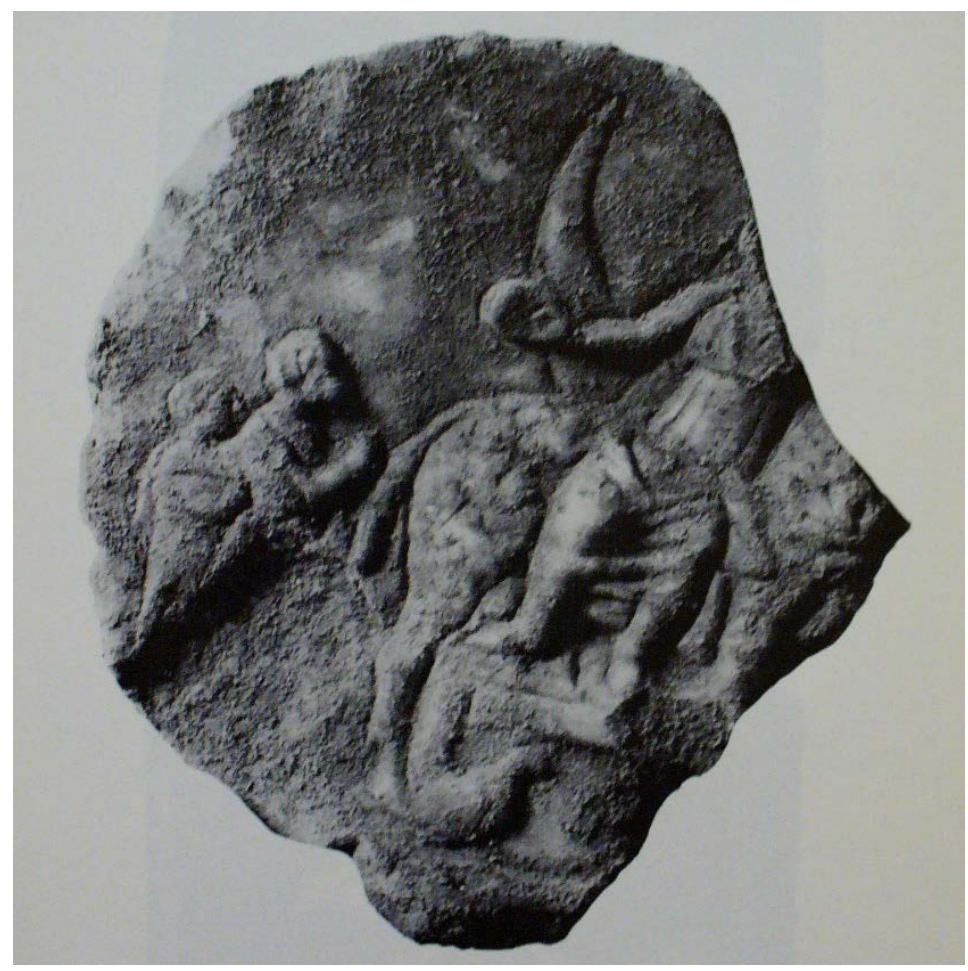

Resim 1: Men ve müritlerini gösteren bir rölyef. Kaynak: CMRDM I, No. 1)

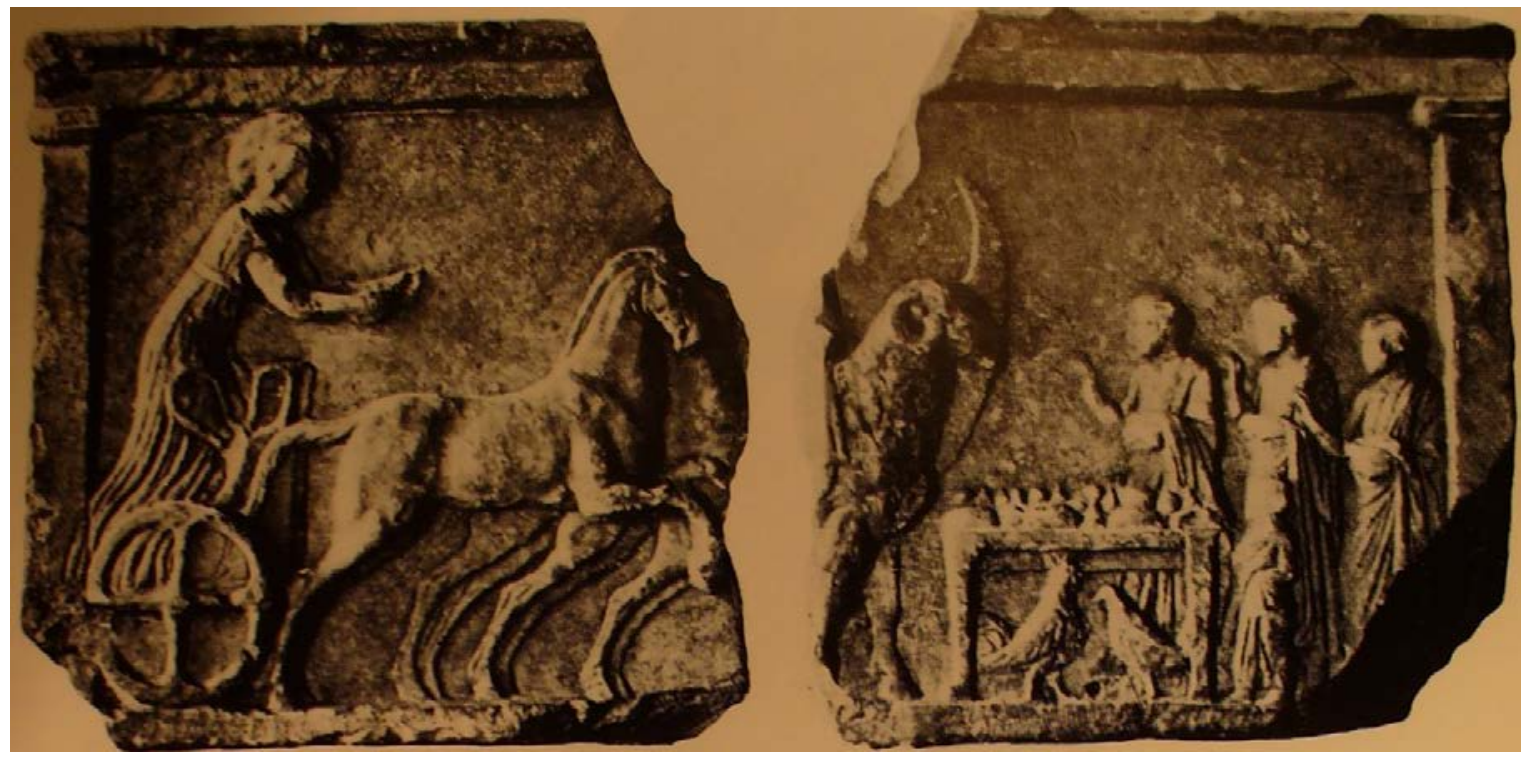

Resim 2: Men ve müritlerini gösteren rölyef. Kaynak: CMRDM I, No. 1) 


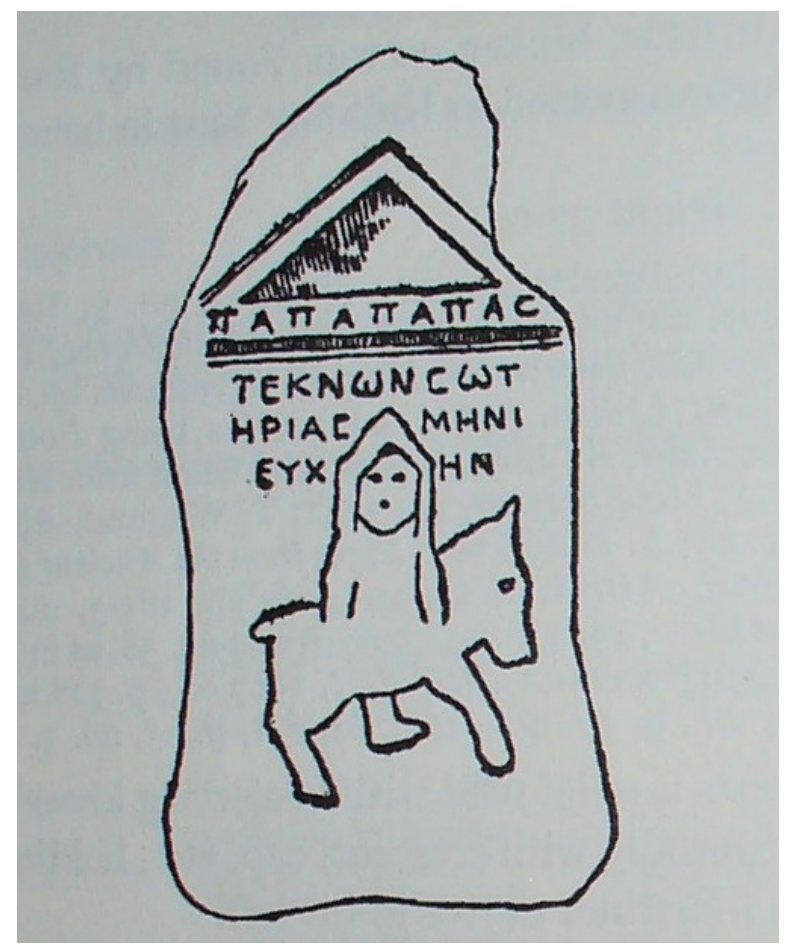

Resim 3: Men adına dikilmiş bir adak. At üstünde Telesphoros kabartması bulunmaktadır. Kaynak: CMRDM I, No.91

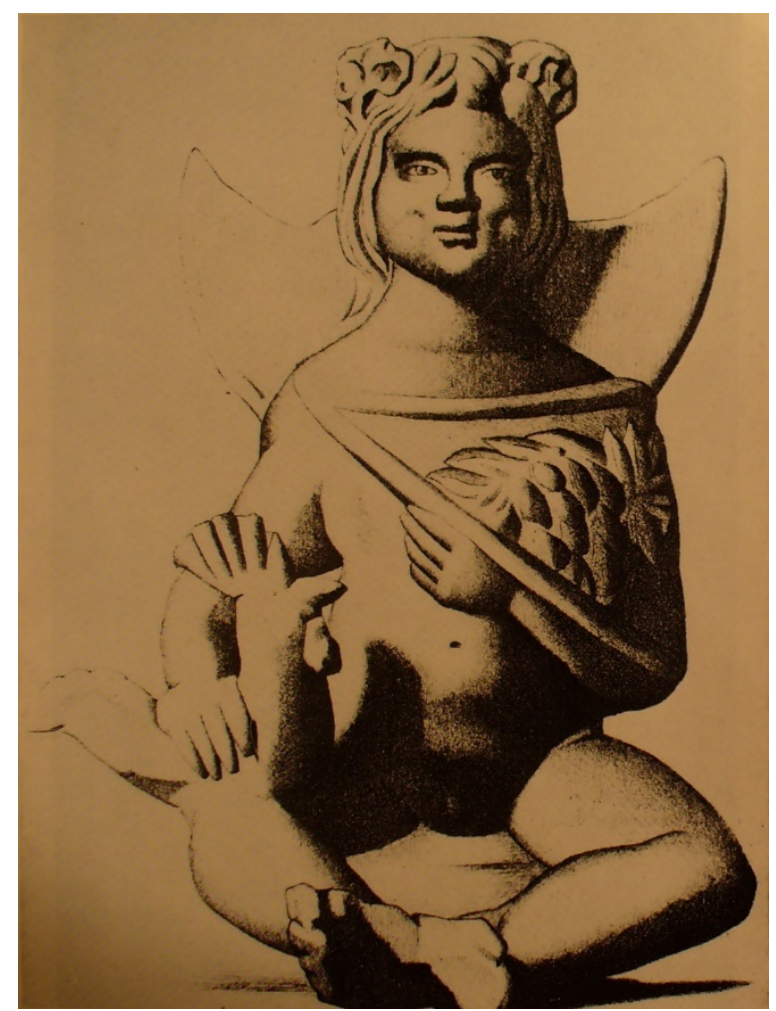

Resim 4: Bebek Men, elinde sembolleri kozalak ve horoz, sırtında ise hilal betimlenmiştir. Kaynak: CMRDM I, No. 64 


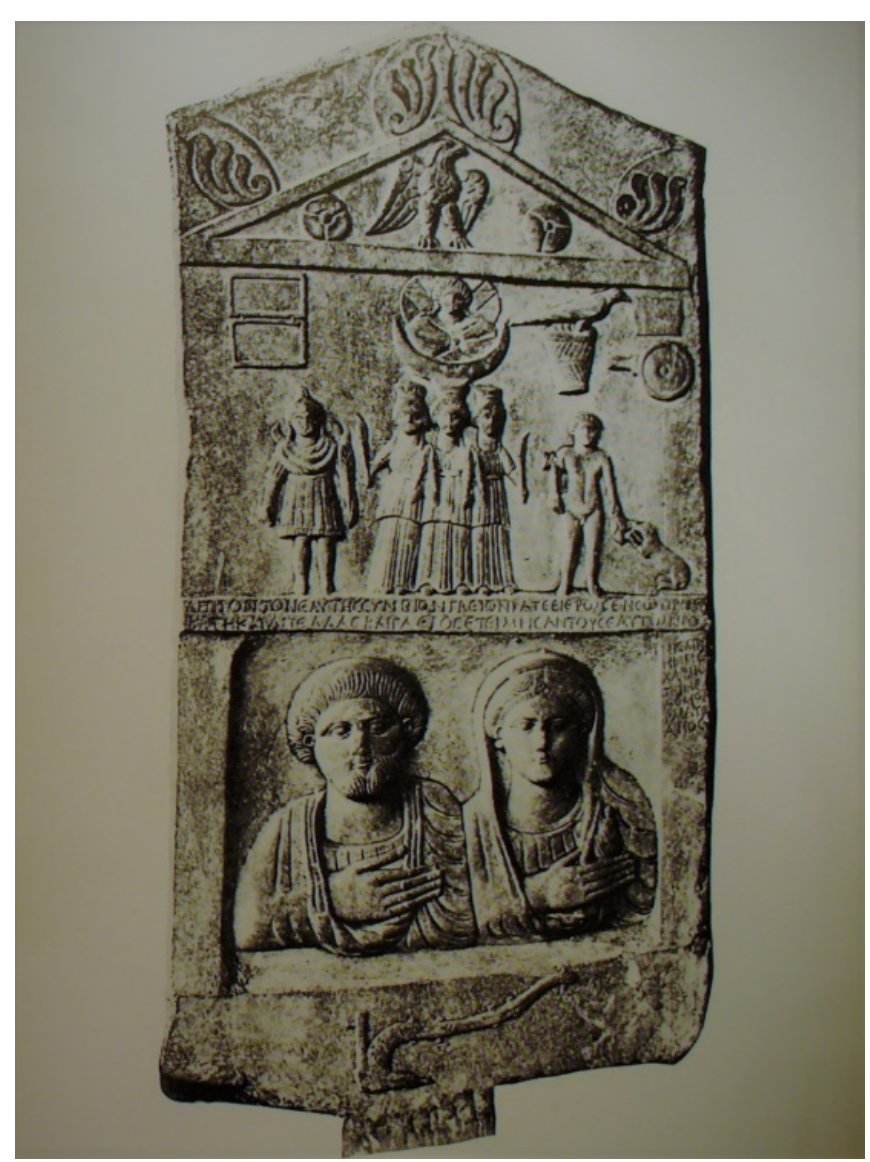

Resim 5: Mezar yazıt1. Üzerinde Men, Hekate ve elinde balta tutan ve köpeği besleyen çocuk figürü. Kaynak: CMRDM I, No.99 